"This is the peer reviewed version of the following article: [AMEDICAL JOURNAL OF

AUSTRALIA, 2020, 213, (6)] which has been published in final form at

[https://onlinelibrary.wiley.com/toc/13265377/2020/213/6] purposes in accordance with Wiley Terms and Conditions for Self-Archiving." 


\title{
Impact of bushfire smoke on respiratory health
}

\author{
Vivek Dharwal, Keshav Raj Paudel, Philip M. Hansbro
}

Centre for Inflammation, Centenary Institute \& University of Technology Sydney, Faculty of Science, Sydney, NSW, Australia

\begin{abstract}
We will define the impact of bushfire smoke of physiology using complimentary in vivo mouse models and ex vivo human studies include effects in asthma and COPD and in different age groups (pregnant, infant, aged). We will define effective preventions/treatments.
\end{abstract}

TO THE EDITOR: The incidence of bushfires, forest fires and wildfires, is increasing globally. Epidemiology shows that those with chronic respiratory diseases (CRDs) are most affected with increased hospitalisations. Despite that, the impacts or safe exposure levels of bushfire smoke (BFS) are not well known [1]. We were recently awarded Medical Research Future Fund's Bushfire Impact Research grant 2020, and in this project we will address: 1. how does BFS exposure affect respiratory health? 2. how does it exacerbate chronic respiratory diseases and affect different age groups? 3. what are the impacts on cells, tissues and molecular pathways? 4. how can we target the effects therapeutically?

BFS is a complex mix of inspirable particles, volatile organics, aldehydes, $\mathrm{CO}$, and particulate matter [2]. Although extensive research evaluating the effects of BFS have not been carried out, studies utilizing cigarette smoke or vehicular particulate matter $\left(\mathrm{PM}_{10 / 2.5}\right)$ show that exposure to these insults induces lung inflammation, oxidative stress, and promotes the progression of chronic respiratory diseases [3; 4]. Further, in vitro studies with healthy human fibroblasts and bronchoepithelial cells show that BFS affects pathways including oxidative stress, barrier function, innate defence, and autophagy [5]. Accordingly, we plan to expose mice to the different PM particles from BFS and will elucidate the acute and prolonged effects on lung inflammation, airway remodelling and lung function. Additionally, by utilizing our mouse model of CRDs (COPD, asthma), and mice at different ages (pregnant, infant, aged) the impact of BFS on predisposition, pathogenesis, and progression of CRDs will be assessed. We will use advanced molecular and multi-'omics (single cell/tissue sequencing, proteomics, epigenetics) technology to elucidate cell and tissue responses. Further, we will define therapeutic avenues for prevention and treatment (antioxidants, metabolic modulators, figure 1).

The outcomes of this project will inform the development of safe exposure guidelines and define preventive/treatment measures. Further, we will address evidence gaps related to harmful health effects of hazardous BS exposure and facilitate government and health agencies to design appropriate policies and preventions/treatments to deal with future BS events.

\section{Reference:}

[1] G. Morgan, V. Sheppeard, B. Khalaj, A. Ayyar, D. Lincoln, B. Jalaludin, J. Beard, S. Corbett, and T. Lumley, Effects of bushfire smoke on daily mortality and hospital admissions in Sydney, Australia. Epidemiology 21 (2010) 47-55.

[2] A.J. De Vos, F. Reisen, A. Cook, B. Devine, and P. Weinstein, Respiratory irritants in Australian bushfire smoke: air toxics sampling in a smoke chamber and during prescribed burns. Arch Environ Contam Toxicol 56 (2009) 380-8. 
[3] B. Jones B, C. Donovan C, G. Liu, H.M. Gomez, V. Chimankar, C.L. Harrison, C.H. Wiegman, I.M. Adcock, D.A. Knight, J.A. Hirota and P.M. Hansbro, Animal models of COPD: What do they tell us? Respirology 22 (2017) 21-32.

[4] J.A. Hirota, M.J. Gold, P.R. Hiebert, L.G. Parkinson, T. Wee, D. Smith, P.M. Hansbro, C. Carlsten, S. VanEeden, D.D. Sin, K.M. McNagny, and D.A. Knight, The nucleotidebinding domain, leucine-rich repeat protein 3 inflammasome/IL-1 receptor I axis mediates innate, but not adaptive, immune responses after exposure to particulate matter under 10 mum. Am J Respir Cell Mol Biol 52 (2015) 96-105.

[5] S.J. Capistrano, R. Zakarya, H. Chen, and B.G. Oliver, Biomass Smoke Exposure Enhances Rhinovirus-Induced Inflammation in Primary Lung Fibroblasts. Int J Mol Sci 17 (2016). 

Figure 1

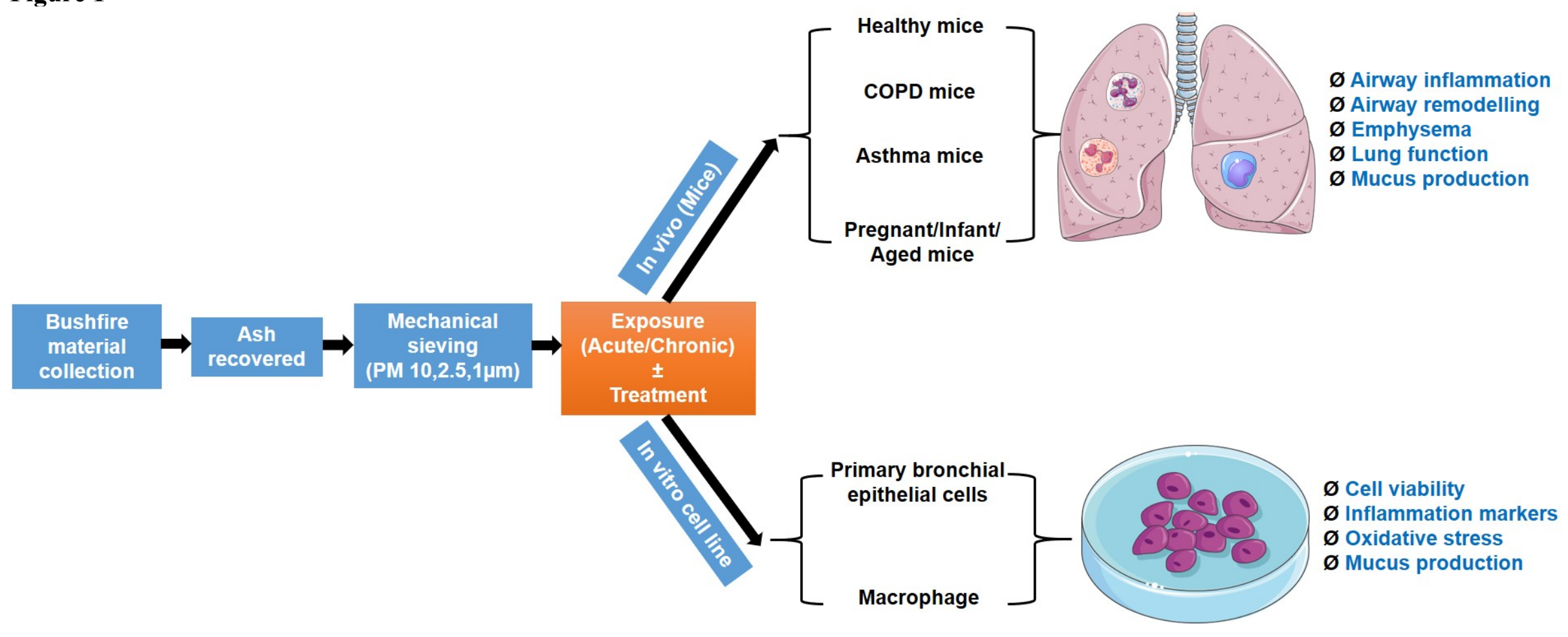

\section{Methodology for evaluating the impact of bushfire smoke}

